\title{
Analyzing the impacts of explosions on dams and levees
}

\author{
J. Parkes, H. Kelly, G. Munfakh \& S. Choi \\ Parsons Brinckerhoff, Inc., USA
}

\begin{abstract}
Infrastructure safety and security is a growing area of engineering analysis. Dams and levees need to be considered as part of these critical infrastructure assessments. In the United States alone, there are over 80,000 dams and 100,000 miles of levees. Over 26,000 of these dams are classified as high or significant hazard. A study has recently been undertaken with the goal of expanding blast security assessments for modeling the impacts of explosions to include analysis of embankment dams and levees. Specific aims of the study include developing reasonably accurate models to assess localized, shallow impacts and developing methods to assess global stability impacts.

Assessing these structures requires a unique combination of understating of blast impacts, soil modelling under high energy dynamic loading, embankment dam failure modes, and conventional geotechnical slope stability. A trial dam section was developed and possible failure mechanisms due to blast impacts were determined. Published numerical soil models, developed and validated for land mine analyses, were evaluated with regard to typical soil properties of embankment dam materials. An applicable soil model was selected, and the numerical trial dam model was analysed for an explosion on the crest. The results were assessed using conventional geotechnical engineering software and engineering judgment. A step-by-step procedure for assessing the impacts of explosions on embankment dams has been developed, and a simplified chart for assessing localized breach potential have been developed. Areas for further study and validation are also identified. The work combines research from military applications with state-of-the-art infrastructure security analyses and conventional geotechnical engineering evaluations.
\end{abstract}

Keywords: dam and levee security, explosions, blast impacts, embankments, simplified charts. 


\section{Introduction}

Infrastructure security is a growing area of concern with focus on high risk structures such as buildings, bridges, and tunnels. Dams and levees need to be included in critical infrastructure assessments. In the United States (US) alone, there are over 87,000 dams [7] and 100,000 miles of levees [1].

Many dams contain public roadways along the crest, and therefore may be accessible as potential terrorist targets. The consequences of a dam or levee failure may include not only the direct loss of a roadway and the loss of a reservoir for water supply or power generation, but also the potentially devastating effect of the sudden uncontrolled release of the reservoir. Over 26,000 dams in the US are classified as either high hazard or significant hazard, meaning failure would result in likely or possible loss of human life [7].

A proper assessment of the impact of explosions on dams and levees requires sophisticated numerical analyses that account for the size, shape, and characteristics of the structure and the location and intensity of the explosive. A failure mode analysis is needed to properly evaluate the potential blast impacts.

\section{Trial dam section and explosive}

\subsection{Trial dam geometry and materials}

Earth embankment dams are by far the most common type of dam, comprising over $85 \%$ of dams in the US [7]. Assessing embankment dams requires a unique understanding of blast loading, soil modeling under high energy dynamic loads, embankment dam failure modes, and conventional geotechnical evaluations.

A trial dam section was developed based on widely used geometric configurations for homogeneous embankment dams, published guidelines [10], and engineering judgment. The height of the dam was limited to 50 feet, since this is generally the upper limit for dams that are designed according to simplified procedures (below 50 feet is generally considered a "small" dam).

The trial dam has a $2.5 \mathrm{H}: 1 \mathrm{~V}$ upstream slope and a $2 \mathrm{H}: 1 \mathrm{~V}$ downstream slope based on minimum published configurations [10]. The crest width is 25 feet, the minimum width assumed for a public roadway consisting of two 10-foot lanes and space for guardrails. The dam is assumed to be built of a mixture of sand and fines, classifying as clayey or silty sand (SC or SM) in accordance with the Unified Soils Classification System (USCS). Minimum freeboard of 5 to 7 feet was used. A conventional slope stability analysis was performed to verify that the dam would have the minimum required factor of safety (FS) of 1.5.

\subsection{Explosive size and location}

The explosive blast is located on the crest surface, which is assumed to have a public roadway. An explosive consistent with a truck or van is assumed, such as the 1993 attack on the World Trade Center and the 1995 attack on the Oklahoma 
City Federal Building. The explosive size is 5,000 pounds of TNT, which is the upper end of the possible range for a van or light truck explosive [6].

Two locations on the crest are assessed: the approximate centers of the upstream and downstream halves of the crest, to model the vehicle in the upstream or downstream lane. The explosive is centered approximately 6 to 6.5 feet from the edge of the crest.

The explosive is centered above the ground surface because the vehicle will have ground clearance and the explosive itself will have mass. The height of the center of the explosive above the ground (the standoff distance) is 4 feet. Only the explosive material (TNT) is modeled. To simplify the model, the vehicle itself is not included. The explosive size and standoff distance are consistent with other transportation infrastructure security assessments. The location of the explosive load and the geometry of the trial dam section are shown in Figure 1.

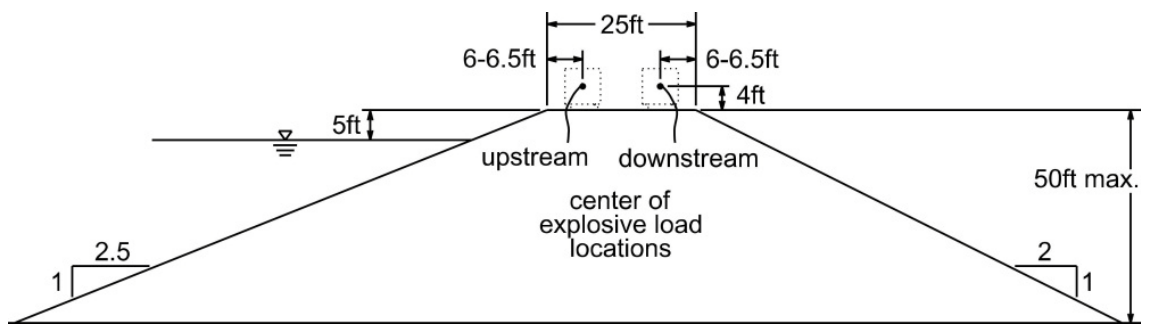

Figure 1: Trial dam geometry and explosive locations.

\section{Failure modes}

A failure mode analysis was performed to determine possible failure scenarios that could result from a blast impact on the dam crest. The blast will produce a crater and ground vibrations/shock. The possible failure modes include:

A. Global stability failure due to the dynamic impact of the explosion (failure during the explosion). Ground shock and vibrations from the explosion may result in internal shearing and/or increases in pore pressure, which may result in global stability failure.

B. Localized failure and breach following the blast. Water inflow into a crater or cracked section leading to progressive erosion, overtopping, and/or internal erosion, developing into an uncontrolled breach.

C. Global stability failure due to the post-blast geometry. Static steady state global stability could be adversely impacted by the post-blast crater or cracked section geometry.

Failure modes for a homogenous embankment dam are shown in Figure 2.

Failure modes B and C may take hours to weeks to develop. Repairs will take time, and the dam may be vulnerable to these failure modes prior to completion of repairs even if there is no failure in the immediate aftermath of the blast. External loading conditions, such as reservoir levels, may change during the event aftermath and repair. All applicable loading conditions should be assessed. 


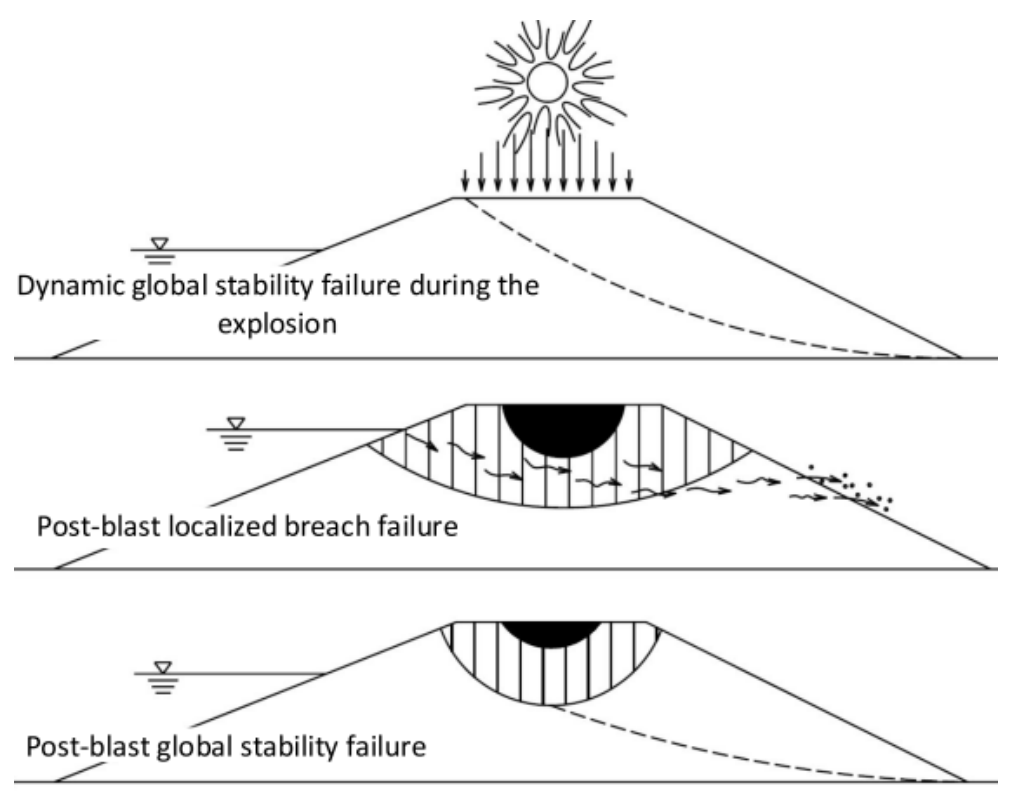

Figure 2: $\quad$ Possible failure modes due to explosion on dam crest.

\section{Blast impact analysis procedure}

A rational multi-stage approach for blast impact assessments on dams, similar in principle to conventional geotechnical dam assessments, is presented herein.

\subsection{Conventional embankment dam assessment approach}

Conventional dam engineering assessments require multiple analyses and software programs. Construction or modification of a dam may include placement of fill, installation of drainage measures, installation of filter measures, construction of cut-off measures, etc. Assessments will include:

1. Deformation analyses - evaluate settlements, lateral spreading, dissipation of excess pore pressures, etc. due to fill.

2. Seepage analyses - evaluate steady state seepage pressures, uplift pressures, and the potential for heave and piping.

3. Slope stability analyses - evaluate global stability and seismic stability.

4. Foundation assessment including settlement, bearing capacity, etc.

5. Multiple loading conditions - conservation pool and probable maximum flood (PMF) conditions reservoir levels, seismic ground motions.

Performing conventional geotechnical assessments requires multiple assessments, loading conditions, and software programs. Simplified methods, such as charts for slope stability or piping/heave, can aid in these assessments. 


\subsection{Proposed approach for embankment dam blast impact assessments}

Similar to conventional geotechnical assessments, blast impact assessments require multiple software programs to evaluate multiple failure modes and loading conditions. The focus of this analysis is the dam itself; impacts to the underlying foundation are not considered. The following multi-staged approach is proposed:

1. Global stability during blast - determine the dynamic load impact (ground motions, dynamic stresses, etc.) and assess global stability.

2. Localized impact and erosive breach potential - determine the impact in the area of the blast (crater depth, cracking potential).

3. Global stability following the blast - assess static steady state global stability of altered dam section due cratered/damaged section.

4. Multiple loading conditions to be assessed - dynamic loads, explosive size and location, reservoir levels, etc.

The assessment above requires specialized software for the blast impact analysis, conventional geotechnical engineering software for global stability, and engineering judgment for assessing the potential for an erosive breach.

Of critical importance is the modelling and analysis of the explosive blast impact; the other assessments build on the results of that analysis.

\section{Numerical blast impact model development}

Conventional geotechnical analyses are based on loads of low to moderate intensity over a period of days to years. Deformations are typically small compared to the size of the structure. By contrast, blast impact analyses involve high intensity loads applied over periods of fractions of a second. Loads may be several orders of magnitude higher than material strengths, and deformations may be large. Transient analyses and non-linear material behaviour are significant aspects of these analyses. Specialized software is needed.

Explicit dynamics software enables analysis of rapid, high intensity loads using complex numerical modelling techniques. Interactions between solids and fluids can be modelled with a Euler-Lagrange coupled analysis. The Euler processor is used to analyze large distortions of fluids and gases, including detonation products. The Lagrange processor is used to model solid structures. Coupled together, a blast impact on a solid structure can be effectively modelled.

The program AUTODYN by ANSYS, Inc. is a commercially available software package for explicit dynamics analyses, including blast impacts. AUTODYN was selected because it is widely used in practice and available research reviewed for this work was also based on AUTODYN.

The results of the AUTODYN models are assessed using conventional geotechnical software for slope stability and engineering judgement. The programs Slope/W and Quake/W by GeoStudio were used for those analyses. 


\subsection{Development of a suitable soil model}

Soils for embankment dam construction are likely to consist of a mixture of sand and fines (silt, clay) and will have a high degree of saturation due to seepage through the embankment or from original construction procedures. Dam soils are generally placed wet of optimum moisture to improve ductility and limit postconstruction settlements after reservoir filling. Therefore, a material model for saturated soils with some fines content is needed for the numerical dam models.

AUTODYN includes a material library for a variety of structural materials. However, soils are not usually considered as a structural material, and the default library in AUTODYN only contains one material model, Sand (Compaction) for soil. This is a compaction model for dry sand, and is therefore not necessarily applicable for the dam models.

Clemson University (CU) and the Army Research Laboratory (ARL) have developed modified AUTODYN compaction soil models for a variety of soils at varying levels of saturation. The compaction model is the most widely used soil material model in military applications [5]. The modified models include dry and fully saturated sand and clayey sand. The research was performed for assessing the effect of soil type with regard to analyzing impacts of landmines.

\subsubsection{Behavior of soil under blast loading}

Soils, particularly sands, consist of a skeleton of solid soil particles with void space between the particles. The void space may be filled entirely with air (dry), water (fully saturated), or a mixture of air and water (partially saturated). Deformation of a sand mass is believed to be a function of two mechanisms [3]:

1. Elastic deformations or fracture of interparticle bonds/forces between sand grains; bonds are a function of surface roughness and binders. Deformations occur at low pressures, fracture occurs at high pressures.

2. Elastic and plastic deformation of the constituent materials in the sand mass. The sand, air, and water may compress in response to load.

For dry soil, interparticle bonds (friction and binder strength) are relatively high, and the mass contains compressible fluid (air) within the pores. For saturated sand, interparticle forces are lower (water reduces friction, buoyancy reduces normal forces), and the pores are filled with incompressible fluid (water). Therefore, both mechanisms of deformation are adversely affected by saturation: interparticle bonds are reduced and compressibility is reduced [2]. Therefore, the overall impact of a blast would be expected to be more significant for saturated sand compared to dry sand.

Research on the effect of clay binder indicates that the clay may coat the sand particles and reduce interparticle friction. However, the addition of up to $15 \%$ clay binder has a less significant effect than the degree of saturation [4]. The effect of sand particle size, particle distribution, and presence of silt or clay on blast response of sand is small compared to the degree of saturation [2]. Material models for saturated soils are significantly different than those for dry soils [4].

There are significant implications of the landmine research with regard to this analysis. The degree of saturation is the most significant aspect of the soil model; the effect of clay binder is not as significant. Dam soils are expected to be at or 
near full saturation, so a saturated soil model is needed. A dry sand model could produce misleading results.

\subsubsection{Material model and validation}

A material library was created for the trial dam analysis. A material model for saturated clayey sand, designated $S C$-Sat, was created based on approximating the published modified compaction CU-ARL saturated clayey sand model.

To verify that the $S C$-Sat material model had been re-created to a reasonable degree of accuracy, the published validation models of a landmine buried in a steel bucket $[3,4]$ were re-created. The model results are consistent with the published results as indicated in Figure 3 for saturated clayey sand.
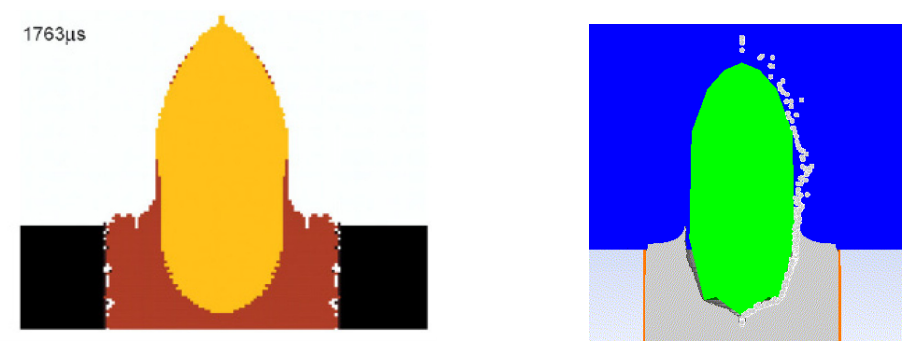

Figure 3: $\quad$ Published CU-ARL saturated sand soil model (left, [5]) and SP-Sat model (right) for a buried landmine explosion

The SC-Sat material model is therefore considered an appropriate model for analyzing saturated clayey sands. It is based on published models for analysis of soils and explosives using the same software and has been field validated.

\subsection{Trial dam model}

Three dimensional numerical models of the trail dam and explosive were developed in AUTODYN using the SC-Sat material. The dam part included 183,000 elements, with additional elements in the Euler space for the air, water, and explosive. Arrays of data collection points were placed under the crest of the dam to record data on pressure, particle velocity, etc. during the blast.

\section{Assessment of blast model results}

\subsection{Assessment of dynamic global stability}

The dynamic global stability is a challenging aspect to evaluate. The stability analyses must be performed with geotechnical slope stability software with data from the numerical blast model. An additional complicating factor is that most slope stability assessments use a 2D cross section whereas the blast model is 3D.

Two methods of analyzing dynamic global stability were evaluated. The first involves modelling the blast as a seismic event. The second involves recording 
ground motion data at specific points in the blast model, importing that data into dynamic stability software and performing the stability analysis.

\subsubsection{Dynamic stability analysis as a seismic event}

To analyze the stability as a seismic event, the overall average acceleration of the dam section is determined from the blast model. AUTODYN can calculate the acceleration of a model part due to dynamic impact; in this case, the part is the dam section. A 50-ft high dam section with a length along centreline of 20 feet was analyzed under a 5,000 lb TNT blast over the crest. The average acceleration of the dam was determined and input into Slope/W as a pseudo-static seismic load.

The results of this analysis showed no significant change in the global stability FS as a result of the explosion.

\subsubsection{Dynamic stability based on ground motions}

The dynamic stability was analyzed using ground motions recorded in the vicinity of the blast. An array of gauge points were created across the crest of the dam to record ground motion data during the blast. The ground motion data was used as input for Quake/W. The Quake/W analysis determined the stresses induced within the dam due to the ground motions; those stresses are exported to Slope/W and the global stability was analyzed.

The result of this analysis indicates a severe drop in overall stability, with a resulting FS value near zero.

\subsubsection{Discussion of dynamic global stability analysis approaches}

The dynamic stability approaches described above provided drastically different results. Both methods have shortcomings that require further assessment.

Analyzing the blast as a seismic event seems appropriate because the ground motions are similar. However, in an earthquake, the accelerations come from the ground under the dam, whereas this approach uses the accelerations at a point on the crest to develop average site accelerations. It is not clear if this approximation is appropriate or not. This approximation does not capture the localized ground motions directly under the blast, which can be several orders of magnitude higher than earthquake-induced motions. Also, because the blast model is a 3D model, the length of the dam along centerline influences the mass of the dam part, and therefore the resulting average acceleration is dependent on the model length. The slope stability analysis is 2D (assumes infinite length).

The analysis based on ground motions also has shortcomings. In AUTODYN and Quake/W, the finite element (FE) mesh of the dam remains intact despite the magnitude of the ground motions. Because the FE meshes remain intact, the ground motions produce high mesh deformations, which result in very high internal dam stresses that cause a severe drop in overall FS. In reality, severe localized ground motions would cause local failure of the soil structure, which would prevent these high stresses from being fully transmitted to deeper depths.

Therefore, neither method appears to adequately assess the dynamic stability. The seismic approach appears to underestimate the impact because it applies a focused impact as an overall averaged site motion. The ground motion approach 
overestimates the impact because it does not account for local soil failure that would prevent full stress transmittal through the dam.

A major issue with assessing the dynamic stability impact is the need for validation of the assessment methods. It is anticipated that the methods described herein can be refined to consider localized impacts, soil failure models, etc. However, without field validation experiments and instrumentation data, attempts at refinement may be unsubstantiated trial and error.

\subsection{Assessment of localized blast impact}

The explosion will create a crater and high deformations in the local area under the blast. Cratering effects have been studied with regard to explosions but mostly for level ground conditions, and little consideration has been given for possible soil structure damage below the crater.

Crack formation in earth dams is a widely recognized concern and may result from tension, differential movements, or shrinkage [8]. In a similar fashion, it is considered possible for cracks to form due to shearing and deformations caused by a blast. For an embankment dam, damage below the crater, such as cracking, may adversely affect the overall structural integrity because of the seepage through the dam. Uncontrolled water inflow, either directly through the crater or through cracks below the crater, can lead to erosion or piping which could eventually result in an uncontrolled breach of the dam.

Criteria for assessing the depth of potential cracking are needed. The use of limiting strain values is proposed. Limiting strains are used in dam engineering for interpretation of shear strengths or assessing compatibility of different soil materials [9]. Such limiting strain values are typically in the range of 5 to $15 \%$. For this work, a range of 10 to $30 \%$ is proposed. Results of the models indicate strains above $30 \%$ are tightly clustered under the crater.

Therefore, the blast models are evaluated based on the effective strain data. Model results indicate that strains may propagate a significant depth below the crater. The localized blast impact therefore consists of a crater and a zone of potential cracking that below the crater.

\subsubsection{Simplified chart for local blast impacts}

A substantial effort is needed to prepare, perform, and interpret a blast impact model. A significant benefit in terms of time and resources could be realized from the development of simplified tools to aid in blast impact assessments. A simplified chart for assessing localized blast impacts has been developed.

The localized impact results in an irregular pattern of deformation due to the slopes of the dam, as can be seen in Figure 4. The maximum depth of strain does not necessarily occur directly under the blast; it may be offset towards the slope due to the lack of external confining pressure. Strains extend laterally and upwards from the maximum depth to the external slopes. The strain propagation is comparable for the blast over the upstream and downstream sides of the crest.

The results of the upstream and downstream analyses were superimposed and a simplified envelope was developed to encompass the results. For simplicity and conservatism, the point of deepest strain is moved to directly beneath the 


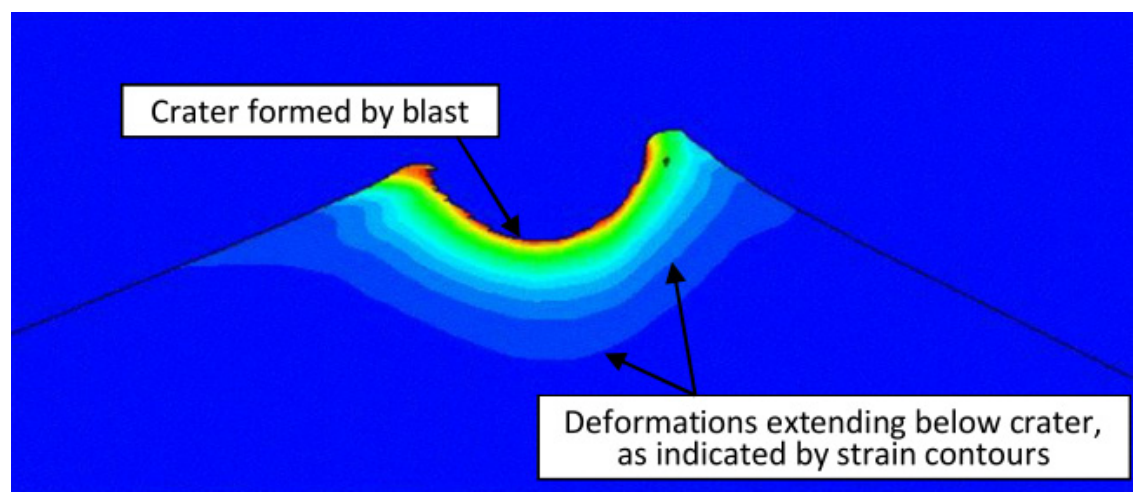

Figure 4: Model results for a blast over the upstream side of the crest, showing effective strain propagation into the dam.

outer edge of the crest. The result is a simplified "zone of potential cracking" that allows an estimate of potential damage due to an explosion on the crest roadway as indicated in Figure 5. A similar procedure is used for developing a depth of potential crater formation based on the $100 \%$ strain contour.

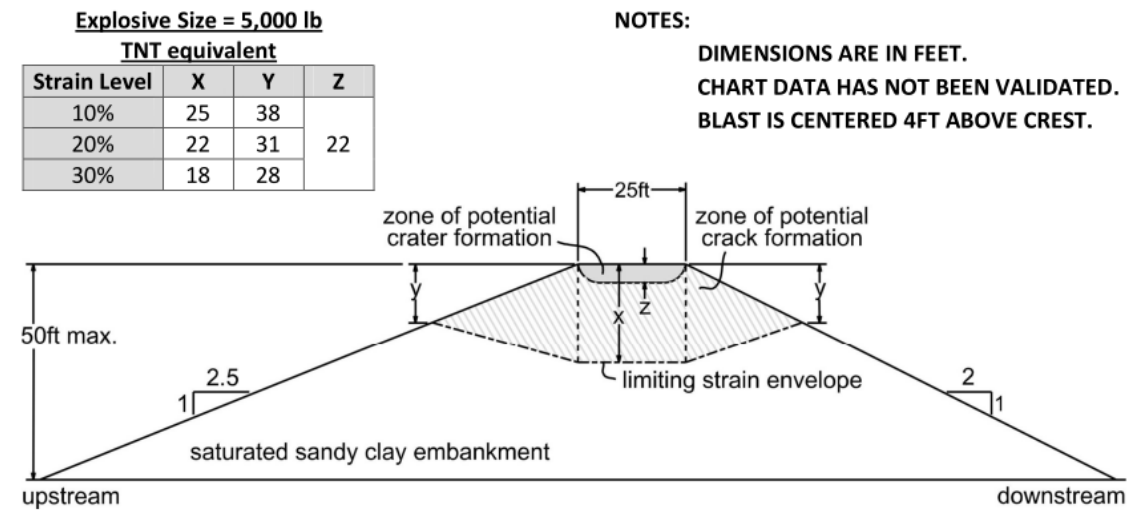

Figure 5: $\quad$ Simplified chart for estimating localized blast impacts.

\subsubsection{Application and limitations of simplified chart}

The determination of which strain to use is a matter of judgment based on the risk tolerance of the dam owner, regulatory agency, and/or engineer and considerations regarding the dam materials, geometry, and failure consequences.

Consideration must be made with regard to whether a dam has adequate freeboard below the depth of applicable strains. If a dam does not have adequate freeboard below the depth of potential cracking, then the owner has to evaluate the next step in their assessment. This might be detailed modeling or exploring potential mitigation measures. The simplified chart provides a tool for a quick initial assessment; it is not intended for final assessment or detailed design. 
Several limitations apply to the use of the chart. These include:

1. The depths indicated do not include any freeboard or any safety margin.

2. The data presented has not been validated by field testing.

3. The potential crack formation depths are based on strains exceeding certain assumed threshold values.

4. Crater depth is based on $100 \%$ strain contour, but this has not been validated as an appropriate prediction of crater depth.

5. The chart is for the trial dam and explosive described previously.

\subsection{Assessment of post-blast global stability}

The explosion results in an altered post-blast geometry that includes a crater and possible cracked section. Post-blast global stability can be assessed using conventional slope stability analysis methods with the post-blast geometry. As with conventional slope stability assessments, cracks should be assumed to be full of water due to seepage or precipitation.

\section{Conclusions and areas for further research}

Analyzing the impacts of explosions on embankment dams and levees requires a complex, multi-stage analysis. The work described herein combines the results of military research and testing, complex numerical modeling, and conventional geotechnical dam engineering assessments. The following conclusions are made:

1. Failure modes include global stability during the blast, global stability following the blast, and localized breach potential.

2. These analyses require multiple software programs. However, the analyses can be performed using commercially available software.

3. The blast impacts should be evaluated using explicit dynamics software to perform Euler-Lagrange coupled analysis.

4. Appropriate soil material models are necessary for the blast model.

5. The degree of saturation is a key aspect of the soil material models. Saturation is more significant than particle size or gradation.

6. Localized blast impacts will extend below the crater. Limiting strains are proposed for evaluating potential crack formation below the crater.

7. Dynamic global stability assessment requires further assessment and field validation testing.

8. Post-blast stability should be assessed using conventional slope stability software and including the crater and possible cracked section.

9. The work described herein has not been validated with field trials or instrumentation data. The simplified chart should be used with caution.

\section{Acknowledgements}

This work is funded through a 2009 William Barclay Parsons Fellowship. The authors would like to thank the PB Career Development Committee for 
supporting this research effort. The authors would also like to thank Rodney Sedillo of the Tampa, Florida office for the global slope stability analyses and Carrie Nicholson of the Baltimore, Maryland office for the graphics.

\section{References}

[1] American Society of Civil Engineers, 2013 Report Card for America's Infrastructure, website URL http://www.infrastructurereportcard.org/factsheet/dams, 2013.

[2] Grujicic, M., Pandurangan, B., and Cheeseman, B.A., "The effect of degree of saturation of sand on detonation phenomena associated with shallow buried and ground laid mines," Shock and Vibration 12, ISSN 10709622/05, 2005.

[3] Grujicic, M., Pandurangan, B., and Cheeseman, B.A., Roy, W. N., and Skaggs, R.R., "Application of the modified compaction material model to the analysis of landmine detonation in soil with various degrees of water saturation," Shock and Vibration 14, ISSN 1070-9622/07, January 2007.

[4] Grujicic, M., B. Pandurangan, N. Coutris, B.A. Cheeseman, W. N. Roy, R.R. Skaggs, "Derivation and Validation of a Material Model for Clayey Sand for Use In Landmine Detonation Computational Analyses", Multidiscipline Modelling in Materials and Structures, Vol. 5 Iss: 4 pp. 311-344, 2007.

[5] Grujicic, M., Pandurangan, B., Qiao, R., Cheeseman, B.A., Roy, W.N., and Skaggs, R.R., Gupta, R. "Parameterization of the Porous-material model for sand with different levels of water saturation," Soil Dynamics and Earthquake Engineering 28, article accepted May 2007.

[6] Parsons Brinckerhoff, Blast Protective Design Seminar, presented at Parsons Brinckerhoff, Baltimore, Maryland, 2009.

[7] United States Army Corps of Engineers, 2013 National Inventory of Dams, website URL http://nid.usace.army.mil, 2013.

[8] United States Army Corps of Engineers, General Design and construction Considerations for Earth and Rock-fill, Manual No. EM 1110-2-2300, 2004.

[9] United States Army Corps of Engineers, Slope Stability, Manual No. EM 1110-2-1902, 2003.

[10] United States Bureau of Reclamation, Design of Small Dams, Second Edition 1973. 